\title{
Management of primary pulmonary hypertension
}

\author{
CELIA M OAKLEY \\ From the Royal Postgraduate Medical School, Hammersmith Hospital, London
}

When Paul Wood first described primary pulmonary hypertension ${ }^{12}$ he believed it to have a vasoconstrictive origin and showed that the pulmonary vascular resistance could be selectively lowered in some but not all of these patients by infusion of acetyl choline into the pulmonary artery ${ }^{3}$ in contrast to patients with the Eisenmenger syndrome, who were invariably unresponsive. ${ }^{34}$ The pathogenesis has since been argued, microthromboembolism and thrombosis in situ having some proponents, but the concept of an increased smooth muscle tone perhaps generated by endothelial damage and platelet activity has gained ground. Efforts to find an effective orally active specific pulmonary arteriolar dilator have continued over the years but with little success, though there has been considerable recent resurgence of interest.

Observations made in beef cattle grazing at high altitude and in humans living and exercising at altitude have shown an individual and species variability suggesting a genetically determined hyperreactivity. 5 This pulmonary hypertension is reversible on return to sea level, and the incidence of primary pulmonary hypertension is seemingly higher in populations living at high altitudes. ${ }^{6}$ Childhood ${ }^{7}$ and familial cases are well known, ${ }^{8}$ and an association with Raynaud's phenomenon was early noted. ${ }^{9}$

In the European epidemic of primary pulmonary hypertension, which was linked with the slimming drug aminorex fumarate, only an estimated $0.2 \%$ of individuals taking the drug developed the disease and the condition was usually reversible. ${ }^{10}$ Primary pulmonary hypertension has also been linked with fenfluramine, ${ }^{11}$ an anorectic which is still available. A concept of idiosyncratic pulmonary hypertension of possible dietary origin grew from this experience and from observations of a malignant type of pulmonary hypertension in rats who had eaten seeds of Crotalaria spectabilis which contains the alkaloid monocrotaline. ${ }^{12}$

Requests for reprints to Dr Celia M Oakley, Royal Postgraduate Medical School, Hammersmith Hospital, Ducane Road, London W12 0HS.
Primary pulmonary hypertension is commoner in women of childbearing age than in any other group, symptoms often develop after puberty or postpartum, and progression of pulmonary vascular disease has been associated with the use of oral contraceptives. ${ }^{1314}$ There is some experimental basis for an association with female hormones, ${ }^{15}$ and the use of a non-virilising antioestrogen such as tamoxifen might even find a place in treatment.

The prognosis of primary pulmonary hypertension is grave, though a few patients remain stable without specific treatment and many survive longer than the median two years of Wood's first cases. ${ }^{16} \mathrm{~A}$ clinical diagnosis can often be made, but it is essential that every patient has full cardiac and pulmonary investigations to ensure that no treatable cause of secondary pulmonary hypertension is left undiscovered.

The place of lung biopsy is controversial. ${ }^{17}$ It has the academic attraction of aiding prediction of likely vasodilator responsiveness as well as the possibility of uncovering a specific underlying cause. Unfortunately, transbronchial biopsy produces too small a sample, and since haemorrhage or pneumothorax would be especially hazardous in these patients an open lung biopsy is safer but it has not yet been shown to justify itself. Pulmonary veno-occlusive disease can usually be recognised clinically, although lung biopsy provides confirmation of this quickly fatal disorder. Medial hypertrophy in primary pulmonary hypertension appears to precede intimal proliferation, obliterative fibrosis, fibrinoid necrosis, and the "plexiform arteriopathy" of Wagenvoort, ${ }^{18}$ but the therapeutic dilemma is how to get hold of patients at a stage of medial hypertrophy before these irreversible changes occur. Symptoms are absent until the disorder is far advanced, and the appearances at necropsy are usually identical to those in the Eisenmenger syndrome. ${ }^{18}$ Fanciful wishful thinking suggests that if increased vasomotor tone and reactivity generate more muscle then this muscle will carry more receptors and at an earlier stage might allow a beneficial selective pulmonary vasodilator response to normally non-selective agents. A recent report describes ${ }^{19}$ a rare case of a 
man in whom sublingual isoprenaline repeatedly induced a transient fall to normal of a moderately increased pulmonary artery pressure and achieved this in four separate studies over a four year period during six years of clinical benefit, a seemingly clear case of reversible vasoconstrictive pulmonary hypertension. Another reported case showed a dramatic response to acetyl choline, but three years later the pulmonary artery pressure was higher and no longer fell with acetyl choline. ${ }^{20}$ These cases, however, differ greatly from most patients with primary pulmonary hypertension, most of whom have higher pulmonary artery pressures when first seen and show at best a much less dramatic response to any drug. ${ }^{21-24}$

Therapeutic endeavour is encouraged by a tew patients who have shown spontaneous regression of primary pulmonary hypertension. ${ }^{25} 26$ Two reported patients had both developed symptoms in childhood ${ }^{25}$ or adolescence, ${ }^{26}$ and one had already advanced to a stage of right ventricular failure when death would have been no surprise. ${ }^{25}$ This shows that clinically advanced disease should not necessarily be equated with irreversibility. In another personal case regression to normal from pulmonary hypertension at systemic level occurred in a woman who had been treated with an early calcium antagonist, prenylamine, prescribed to her years earlier for angina presumed to be from the right ventricle.

Vasodilator drugs can improve cardiovascular function only in patients with primary pulmonary hypertension who have a high level of reversible vasomotor tone in the pulmonary bed and, conversely, they must have a detrimental effect in patients with irreversible anatomical changes. ${ }^{22} 27$ Selective systemic vasodilatation will cause hypotension and may be fatal unless left ventricular filling increases. The right ventricular output is characteristically very low in primary pulmonary hypertension, and it may paradoxically fall further after the chosen vasodilator if the drug either reduces venous return and right ventricular filling pressure or if it has negative inotropic properties and reduces right ventricular contractile force without relieving its afterload. Thus nifedipine has been reported to cause a reduction in cardiac output associated either with a fall in right atrial pressure ${ }^{28}$ from systemic vasodilatation or with an increase in right atrial pressure associated with evidence of right ventricular failure. ${ }^{29}$ These adverse effects are not apparent when nifedipine unloads the right ventricle by pulmonary vasodilatation and the cardiac output rises. ${ }^{3031}$ In just the same way net benefit from nifedipine has been reported in left ventricular failure.

Patients with a patent foramen ovale were early observed by Wood to have a better prognosis; they can keep the left ventricle filled and are less likely to become hypotensive or to die suddenly. In such patients a favourable response to a drug may be seen by an increase in systemic arterial oxygen content while a fall signals selective systemic vasodilatation with an increase in right to left shunting. Unlike in mitral stenosis successful reduction in pulmonary vascular resistance in primary pulmonary hypertension is not normally associated with a fall in systemic arterial saturation, caused by perfusion of underventilated lung, provided the cardiac outpu. rises.:- Recruitment of previously unperfused vessels rather than a general relaxation of vasomotor tone may possibly account for some observed rises in cardiac output associated with a fall in both systemic and pulmonary artery pressures. This phenomenon may explain refractory hypotension and death reported with incremental dosage of a drug which had seemed to be well tolerated ${ }^{27}$ or there may be rapid attenuation of an initially favourable response. ${ }^{32}$ In some patients given a vasodilating inotropic agent such as isoprenaline the pulmonary artery pressure has fallen $^{33}{ }^{34}$; in others it has caused a rise in right ventricular output with a deleterious rise in pulmonary artery pressure $^{35}$ associated with failure to dilate the lung vessels; calculated resistance may stay the same or actually fall, tachycardia is usual, and tremor uncomfortable.

Conflicting responses (many favourable but some adverse) have been reported from acute studies of many different vasodilators either infused into the pulmonary artery or given intravenously: acetyl choline, ${ }^{4}$ tolazoline, ${ }^{36}$ phentolamine, ${ }^{37-39}$ isoprenaline, ${ }^{33} 34$ and diazoxide, ${ }^{40^{-43}}$ but long term oral treatment has been disappointing. Prostacyclin suggested itself as a suitable drug for acute assessment, ${ }^{44-46}$ being a powerful relaxant of vascular smooth muscle, and it may be particularly relevant if abnormal platelet behaviour is important in the pathogenesis of primary pulmonary hypertension. Although non-selective, prostacyclin is easily titrated and can be used safely for assessing drug responsiveness. Since the vasodilator effect of hydralazine is thought to be mediated by endogenous prostaglandins its use in primary pulmonary hypertension was attractive, ${ }^{47-49}$ but as with nifedipine both beneficial and serious adverse reactions have been reported. Recently, the use of diltiazem 5051 and captopril 5253 have been reported. Diltiazem has the least myocardial depressant effect of the calcium antagonists so is the most attractive for use in primary pulmonary hypertension. Enalapril with its longer action may prove preferable to captopril. New synthetic beta adrenergic agonists such as pirbuterol, ${ }^{54}$ with a high selectivity for pulmonary beta ${ }_{2}$ receptors, will no doubt be "better" than isoprenaline.

Sadly, structural obliteration of the pulmonary cir- 
culation is probably the major factor by the time most patients are seen, but even if only $5 \%$ or $10 \%$ of patients are capable of pulmonary vasodilatation every patient with primary pulmonary hypertension should be given the benefit of an inpatient, invasive, acute haemodynamic assessment. There is yet no guide to the agent of choice. Positive responders probably respond to each of the drugs, and those few more fortunate patients stand to gain a great deal from long term treatment. There is no role for digitalis in patients with sinus rhythm, and diuretic dosage should be minimal. Oral anticoagulants should usually be given to prevent secondary thromboembolism as in other low output states. Oxygen inhalation ${ }^{55}$ at home aided by an oxygen condenser may be beneficial in some. Portable oxygen is helpful for patients with arterial desaturation. Patients with primary pulmonary hypertension should be screened for evidence of collagen vascular disease, but it is even more important for patients who present with symptoms of a connective tissue disorder to be investigated for pulmonary hypertension at a time when vasodilator treatment may be most rewarding; they are patients with systemic lupus erythematosus ${ }^{56}$ or scleroderma, ${ }^{57}$ particularly in the CREST syndrome or mixed connective tissue disorder and rheumatoid disease. ${ }^{58}$ Patients with systemic lupus erythematosus who are found to have the lupus anticoagulant should be early suspects for pulmonary hypertension; it is of interest that nifedipine is the usual drug of choice for the treatment of Raynaud's phenomenon and might be preventing the development or progression of associated pulmonary hypertension in some of these patients.

Heart and lung transplantation is the final radical treatment for pulmonary vascular disease in primary pulmonary hypertension and the Eisenmenger syndrome and may offer the only realistic hope for palliation of advanced disease.

\section{References}

1 Wood P. Congenital heart disease. $\mathrm{Br} M e d \mathcal{F}$ 1950; ii: 693-9.

2 Wood P. Pulmonary hypertension. Br Med Bull 1952; 8: 348-53.

3 Wood $P$. The vasoconstrictive factor in pulmonary hypertension. In: Adams WR, Veith I, eds. Pulmonary circulation. New York: Grune and Stratton, 1959: 294 301.

4 Wood P. Pulmonary hypertension with special reference to the vasoconstrictive factor. $\mathrm{Br}$ Heart $\mathcal{F}$ 1958; 20: 55770.

5 Grover RF, Reeves JT, Will DH, Blount SG Jr. Pulmonary vasoconstriciton in steers at high altitude. $\mathcal{F} \mathrm{Appl}$ Physiol 1963; 18: 567-74.

6 Vogel JHK, Weaver WF, Rose RL. Blount SG Jr,
Grover RF. Pulmonary hypertension on exertion in normal man living at 10,150 feet (Leadville, Colorado). Medicina Thoracalis 1962; 19: 461-77.

7 Farrar JF, Reye RDK, Stuckey D. Primary pulmonary hypertension in childhood. Br Heart f 1961; 23: 605-15.

8 Melmon KL, Braunwald E. Familial pulmonary hypertension. $N$ Engl f Med 1963; 269: 770-5.

9 Wade G, Ball J. Unexplained pulmonary hypertension. Qf Med 1957; 26: 83-119.

10 Kay JM, Smith P, Heath D. Aminorex and the pulmonary circulation. Thorax 1971; 26: 262-70.

11 Douglas JG, Munro JF, Kitchin AH, Muir AL, Proudfoot AT. Pulmonary hypertension and fenfluramine. $\mathrm{Br}$ Med f 1981; 283: 881-3.

12 Meyrick B, Reid L. Development of pulmonary arterial changes in rats fed crotalaria spectabilis. Am $\mathcal{F}$ Pathol 1979; 94: 37-48.

13 Oakley CM, Somerville J. Oral contraceptives and progressive pulmonary vascular disease. Lancet 1968; i: 890-3.

14 Kleiger RE, Boxer M, Ingham R, Harrison DC. Pulmonary hypertension in patients using oral contraceptives. Chest 1976; 69: 143-7.

15 Irey $\mathrm{N}$, Norris $\mathrm{HJ}$. Intimal vascular lesions associated with female reproductive steroids. Arch Pathol 1973; 96: 227-34.

16 Suarez LD, Sciandro EE, Llera JJ, Perosio AM. Longterm follow-up in primary pulmonary hypertension. $\mathrm{Br}$ Heart f 1979; 41: 702-8.

17 Hawarth SG. Primary pulmonary hypertension. Br Heart f 1983; 49: 517-21.

18 Wagenvoort CA, Wagenvoort N. Primary pulmonary hypertension: a pathologic study of the lung vessels in 156 clinically diagnosed cases. Circulation 1970; 42: 1163-84.

19 Pietro DA, La Bresh KA, Shulman RM, Folland ED, Parisi AF, Sasahara AA. Sustained improvement in primary pulmonary hyperiension during six years of treatment with sublingual isoproterenol. $N \mathrm{Engl} \mathcal{F} \mathrm{Med}$ 1984; 310: 1032-4.

20 Samet P, Bernstein WH. Loss of reactivity of the pulmonary vascular bed in primary pulmonary hypertension. Am Heart f 1963; 66: 197-9.

21 Kanemoto N, Sasamoto H. Hemodynamic changes in primary pulmonary hypertension with special reference to prognosis. Kokyu To funkan 1977; 25: 1017-21.

22 Reeves JT. Vasodilator therapy for pulmonary hypertension [Letter]. $N$ Engl f Med 1980; 302: 1261-2.

23 Elkayam U. Vasodilator therapy in primary pulmonary hypertension. Chest 1981; 79: 253-4.

24 Fishman AP. Primary pulmonary hypertension: more light or more tunnel? Ann Intern Med 1981; 94: 815-7.

25 Bourdillon PDV, Oakley CM. Regression of primary pulmonary hypertension. Br Heart $\mathcal{f}$ 1976; 38: 264-70.

26 Fujii A, Rabinovitch M, Matthews EC. A case of spontaneous resolution of idiopathic pulmonary hypertension. Br Heart $\mathcal{f}$ 1981; 46: 574-7.

27 Packer M, Greenberg B, Massie B, Dash H. Deleterious effects of hydralazine in patients with pulmonary hypertension. $N$ Engl f Med 1982; 306: 1326-31.

28 Kastanos N, Estopa R, Rodríguez-Roisen R, AgustíVidal A. Hydralazine in pulmonary hypertension [Let- 
ter]. N Engl f Med 1982; $307: 1215$.

29 Packer M, Greenberg B, Massie B, Dash H. Hydralazin in pulmonary hypertension [Letter]. N Engl F Med 1982; 307: 1215-6.

30 Camerini F, Alberti E, Klugmann S, Salvi A. Primary pulmonary hypertension: effects of nifedipine. $\mathrm{Br}$ Heart f 1980; 44: 352-6.

31 Wise JR Jr. Nifedipine in the treatment of primary pulmonary hypertension. Am Heart f 1983; 105: 693-4.

32 Wood BA, Tortoledo F, Luck JC, Fennell WH. Rapid attenuation of response to nifedipine in primary pulmonary hypertension. Chest 1982; 82: 793-4.

33 Daoud FS, Reeves JT, Kelly DB. Isoproterenol as a potential pulmonary vasodilator in primary pulmonary hypertension. Am $\mathcal{F}$ Cardiol 1978; 42: 817-22.

34 Shettigar UR, Hultgren HN, Specter M, Martin R, Davies DH. Primary pulmonary hypertension: favourable effect of isoproterenol. $N$ Engl $\mathcal{F}$ Med 1976; 295: 1414-5.

35 Elkayam U, Frishman WH, Yoran C, Strom J, Sonnenblick EH, Cohen MN. Unfavourable haemodynamic and clinical effects of isoproterenol in primary pulmonary hypertension. Cardiovascular Medicine 1977; 3: 1177-80.

36 Rudolph AM, Paul MH, Sommer LS, Nadas AS. Effects of tolazoline hydrochloride (priscoline) on circulatory dynamics of patients with pulmonary hypertension. Am Heart $\mathcal{F}$ 1958; 55: 424-32.

37 Ruskin JN, Hutter AM Jr. Primary pulmonary hypertension teated with oral phentolamine. Ann Intern Med 1979; 90: 772-4.

38 Cha SD, Kirschbaum M, Maranhao V, Paine E, Gooch AS. Phentolamine for primary pulmonary hypertension [Letter]. Ann Intern Med 1979; 91: 927-8.

39 Cohen ML, Krozon I. Adverse hemodynamic effects of phentolamine in primary pulmonary hypertension. Ann Intern Med 1981; 95: 591-2.

40 Wang SWS, Pohl JEF, Rowlands DJ, Wade EG. Diazoxide in treatment of primary pulmonary hypertension. $\mathrm{Br}$ Heart $\mathcal{F}$ 1978; 40: 572-4.

41 Rubino JM, Schroeder JS. Diazoxide in treatment of primary pulmonary hypertension [Letter]. Br Heart $\mathcal{F}$ 1979; 42: 362-3.

42 Honey M, Cotter L, Davies N, Denison D. Clinical and haemodynamic effects of diazoxide in primary pulmonary hypertension. Thorax 1980; 35: 269-76.

43 Klinke WP, Gilbert JAL. Diazoxide in primary pulmonary hypertension. $N$ Engl f Med 1980; 302: 91-2.

44 Hermiller JB, Bambach D, Thompson MJ, et al. Vasodilators and prostaglandin inhibitors in primary pulmo- nary hypertension. Ann Intern Med 1982; 97: 480-9.

45 Rozkovec A, Minty K, Stradling J, et al. Value of acute vasodilator studies in management of primary pulmonary hypertension [Abstract]. Circulation 1982;-66 (suppl II): 49.

46 Rubin LJ, Groves BM, Reeves JT, Frosolono M, Handel F, Cato A. Prostacyclin-induced acute pulmonary vasodilation in primary pulmonary hypertension. Circulation 1982; 66: 334-8.

47 Rubin LJ, Peter RH. Oral hydralazine therapy for primary pulmonary hypertension. $N$ Engl F Med 1980; 302: 69-73.

48 Kronzon I, Cohen M, Winer HE. Adverse effect of hydralazine in patients with primary pulmonary hypertension. FAMA 1982; 247: 3112-4.

49 Lupi-Herrera E, Sandoval J, Seoane M, Bialostozky D. The role of hydralazine therapy for pulmonary arterial hypertension of unknown cause. Circulation 1982; 65: 645-50.

50 Crevey BJ, Dantzker DR, Bower JS, Popat KD, Walker SD. Hemodynamic and gas exchange effects of intravenous diltiazem in patients with pulmonary hypertension. Am 7 Cardiol 1982; 49: 578-83.

51 Kambara H, Fujimoto K, Wakabayashi A, Kawai C. Primary pulmonary hypertension: beneficicial therapy with diltiazem. Am Heart f 1981; 101: 230-1.

52 Ikram H, Maslowski AH, Nicholls MG, Espiner EA, Hull FTL. Haemodynamic and hormonal effects of captopril in primary pulmonary hypertension. Br Heart $\mathrm{f}$ 1982; 48: 541-5.

53 Kokubu T, Kazatani Y, Hamada M, et al. Is captopril effective in primary pulmonary hypertension? $\mathcal{F p n ~} \mathrm{Circ} \mathcal{F}$ 1982; 46: 1095-7.

54 Moore PF, Constantine JW, Barth WE. Pirbuterol, a selective beta ${ }_{2}$ adrenergic bronchodilator. F Pharmacol Exp Ther 1978; 207: 410-18.

55 Nagasaka Y, Akutsu H, Lee YS, Fujimoto S, Chikamori J. Longterm favorable effect of oxygen administration on a patient with primary pulmonary hypertension. Chest 1978; 74: 299-300.

56 Asherson RA, Mackworth-Young CG, Boey ML, et al. Pulmonary hypertension in systemic lupus erythematosus. Br Heart $\mathcal{F}$ 1983; 287: 1024-5.

57 Rozkovec A, Bernstein R, Asherson RA, Oakley CM. Vascular reactivity and pulmonary hypertension in systemic sclerosis. Arthritis Rheum 1983; 26: 1037-40.

58 Gardner DL, Duthie JJR, Macleod J, Allan WSA. Pulmonary hypertension in rheumatoid arthritis. Scott Med f 1957; 2: 183-8. 